\title{
Social Media as a Marketing Tool: A Study with Reference to First Time Voters in the University of Colombo
}

\author{
Chandrasekara R. ${ }^{1}$, Dharmadasa M.P.P. ${ }^{2}$ \\ ${ }^{1}$ Lecturer, ${ }^{2}$ Senior Lecturer \\ Department of Marketing, Faculty of Management and Finance, University of Colombo
}

\begin{abstract}
Today's political marketers are successfully driving target voters towards favourable attitude change (Henneberg, 2002). The first time voter group is an important target market in political marketing, and as identified in literature, social media and peer groups play a major role in influencing political attitudes of first time voters.

This study aims to explore how first time voters form their political attitudes, from exposure to social media political campaigns and from online peer interactions. The Processes of Compliance, Identification and Internalization in the Social Influence theory was used as a theoretical lens; data was gathered through 21 semi-structured in-depth interviews, and thematic Analysis was used to analyze data, under an exhaustive coding process.

Research findings indicate that first time voters' political attitudes were mostly formed and driven on achieving personal goals; that is, individuals were more concerned with the long lasting effects of value congruence (Internalization), rather than the social effect (Compliance) or social anchorage (Identification) of behaviour. Further, online peer interactions on social media was a strong source of influence (for political attitude formation), than mere passive exposure to political campaigns on social media. The most influential peers were 'high status peers' with direct political connections, acting as strong opinion leaders. Furthermore, first time voters are influenced due to the perceived credibility of peers (through Internalization), as opposed to their controlling power (Compliance) or attractiveness (Identification).
\end{abstract}

Key Words: Social Media, Online Peer Influence, Political Socialization, Political Attitude formation 


\subsection{Introduction}

Political Marketing is a growing trend throughout the world and within the current ICT enabled society, an increasing number of politicians are using social media as a marketing / socialization tool to communicate with the electorate (Vergeer, Hermans, \& Sam, 2011). This is apparent even in Sri Lanka, where politicians are especially targeting the youth in the country, who are heavy users of social media networks, and represent the total voting population significantly.

Previous literature highlights the prominence of socialization agents in the consumer decision process (Bush, Smith \& Martin, 1999; Bjurström, 2002). As an extension of Socialization, Consumer Socialization is more meaningful to marketers, which is defined by Ward (1980), as a "process by which young people acquire skills, knowledge, and attitudes relevant to their functioning as consumers in the marketplace" (p.2). Among relatively influential agents of socialization, previous studies have examined the influence of family, media, and peers on the development of consumer decisions patterns (Bush et al., 1999; Rao, Childers, \& Dutta, 1991).

\subsection{Social media as a consumer socializing agent}

With the development of Information and Communication Technology (ICT) traditional mass media is substituted by social media. The term social media can take several forms. The more popularly known social media software applications range from Facebook, My Space, Twitter, Flicker, Hi5, LinkedIn, Wikimedia, Picasa, You Tube and Skype. Sri Lanka shows a comparably large internet user growth rate of $857.6 \%$ for the period 2000-2009 (http://www.internetworldstats.com/stats3.htm, 2012) and the internet penetration rate for the country in 2010 was 8.3, which is an increase from 5.5 in 2009. It is also believed that before 2015, more than $50 \%$ of the world's internet users including Sri Lankan users, will be using Facebook (The World Fact Book, 2010). For instance, as at the $1^{\text {st }}$ of March, 2010, there were $41.54 \%$ of Facebook users out of the total number of online users in Sri Lanka (The World Factbook, 2010).

\subsection{Peer groups as a consumer socialization agent}

The six markets model, developed by Christopher et al. (1991), highlights the various groups of stakeholders, including peer groups, that can be of critical importance to a commercial organization (as cited in Dean \& Croft, 2000). Extant literature discusses the important role 
played by peer groups in influencing adolescents towards making consumption decisions about products and brands (Shim \& Koh, 1997).

Interestingly, it is observed that interactions within peer groups can even lead to active interaction about consumption matters with other 'agents' such as the mass media, by making an individual more aware of the consumer environment. Owen (2008) suggests that the political knowledge, attentiveness to politics, and preferences of young people were influenced by media both directly and through the arbitration of other agents.

\subsection{Attitude formation through Political Socialization}

Hess and Torney (2006) extensively discuss how the political socialization process of a young individual's life, leads him/her to form a set of attitudes about a political system. As identified in research, one of the earliest agents of attitude formation is our parents, later followed by our peers and the (social) media (Tolbert \& McNeal, 2003). It is therefore important, for political marketers to understand how the socialization effects of social media and peer interaction through social media, can influence political attitude formation.

\subsection{Problem Statement}

A nation-wide survey conducted on 'The Youth and the Challenge of Democratization' (Mitra et al., 2002) in Sri Lanka, shows that while the level of interest in politics among youths is an important prerequisite for political participation in a country, out of a selected sample of 1836 young people between the ages of $15-24,56 \%$ stated they were not interested in politics or public affairs of the country; Whereas in another survey done on 'Youth, Conflict and Social Transformation in Sri Lanka' (Thangarajah, 2002), a majority of $57.7 \%$ of the youth said they have no interest in politics.

Despite the above evidence, a high level of political interest was displayed among the online behaviour of the youth population, in the 2010 presidential election. For instance, more than $70 \%$ of the active participators on Facebook, supporting President Mahinda Rajapakshe were the Sri Lankan youth population between 18-30 years (National Youth Council, Sri Lanka, 2010). The National Youth Council, who launched the online political campaign for the governing party during the presidential election (2010), targeted and made use of the Sri Lankan youth as influencing socialization agents on social media. 
The evidence above is rejuvenated by the findings of a pilot study conducted, where the researcher finds that a wide range of social media applications (Facebook being the most popular) were being extensively used by young university undergraduates at an average frequency of 2-3 hours a day and 4-5 days a week. Despite a general lack of interest in politics, all respondents were aware of political campaigns conducted on social media networks during the 2010 presidential election and were active social media participants.

As interest in politics is considered to be a prerequisite in attitude formation (Mitra et al., 2002; Bush et al., 1999; Al-Rafee \& Cronan, 2006), the need to explore the role of social media as a socialization agent on the attitude formation of the youth population, is important. Based on above arguments, this study addresses the problem of "how do social media and peer interactions through social media, influence attitude formation, in the context of political marketing".

\subsection{Research Questions}

1. How does exposure to social media, influence attitude formation of first time voters in Sri Lanka?

2. How do peer interactions through social media, influence attitude formation of first time voters in Sri Lanka?

\subsection{Literature Review}

\subsection{Emergence of social media as a political marketing tool}

Social media is an umbrella term that defines the various activities which integrate technology, social interaction, and the construction of words, pictures, videos and audios (Sampath, 2010), using low cost tools. These tools are typically internet or mobile based.

Supporting its contribution to politics, literature suggest that those individuals who engage in internet activities such as using e- mail and chat-rooms were more likely to be engaged in a variety of political activities (Weber \& Bergman, 2001). As a recent extension of the internet, the use of social media is increasingly becoming popular as a tool for political candidates to reach the mass public and interact with them. In the recent presidential election held in Sri Lanka, the election campaigns demonstrated the two main candidates and their supporters made wide use of social media sites such as Facebook, Youtube and Twitter, together with unsolicited SMS messages and pre-recorded phone messages. Although the access to social 
media websites is generally limited to Colombo and a few of other larger towns, and primarily confined to a younger, english-literate demographic, both candidates enthusiastically reached out to this group of voters, many of whom were likely first time voters (Commonwealth Report, 2010).

Modern day politicians are discovering how they can use social media networks to encourage conversation among socially influential users, while also using it to ignite off-line word of mouth conversations. Research claims that the more interaction that is enabled or built in to social media content, the more offline word of mouth is stimulated (Maltoni, 2010). One of the core objectives of the National Youth Council, during the 2010 presidential election, was to use the mentality and attitudes of the IT literate population of Colombo, to make an influence in rural areas.

\subsection{Political Attitude formation}

Literature identifies that political socialization, helps individuals acquire information, beliefs, attitudes and values about a political system, and the end product of political socialization is a set of attitudes towards the political system. The ultimate objective in political marketing, as with the marketing of any good or service would be to achieve attitude formation or change in the consumer. Katz (1960) defines attitude as the predisposition of an individual to evaluate some symbol or object or aspect of his world in a favourable or unfavourable manner.

\subsection{Theory of social influence}

Attitudinal change is a type of change in which the change agent exercises social influence. In direct connection with the social learning theory which lays the foundation for the consumer / political socialization process, Kelman's (1958) theory of social influence introduces three influence processes: compliance, identification and internalization.

Compliance occurs when individuals accept influence because they hope to achieve a favourable reaction from another person or a group. The induced behavior is adopted not because the consumer believes it is inherently beneficial, but because it produces a desirable consequence regardless of his private beliefs (Kelman, 1958). Thus, a voter's attitudes may be formed on being exposed to a social media political campaign or through the influence of online peer interactions, because he/she wants to achieve a favourable reaction from peers, or obtain rewards /avoid penalties of any kind offered by social media marketing campaigns. 
Alternatively, identification takes place when an individual accepts influence because he wants to establish or maintain a satisfying, self-defining relationship to another person /group. He adopts the induced behavior because it is associated with the desired relationship. In this context, a voter having an attractive role relationship with peers, will be induced due to peer interactions, or one who is seeking confirmation of self-identity towards molding his self-image (Katz, 1960), will be induced due to social media exposure regardless of his/her personal beliefs.

The third process, Internalization, occurs when the consumer adopts the induced behavior because it fits in with an existing value system or is intrinsically satisfying (Kelman, 1958). He adopts the induced behavior because it is congruent with his value system. The process of Internalization starts by learning what the induced behaviour is, attempting to understand why it is of value, and finally deciding to internalize it in to one's own value system.

\subsection{Methodology}

\subsection{Conceptualization}

The main objective of the researcher is to find how exposure to social media political campaigns and peer interactions through social media, form attitudes of first time voters through the processes of social influence.

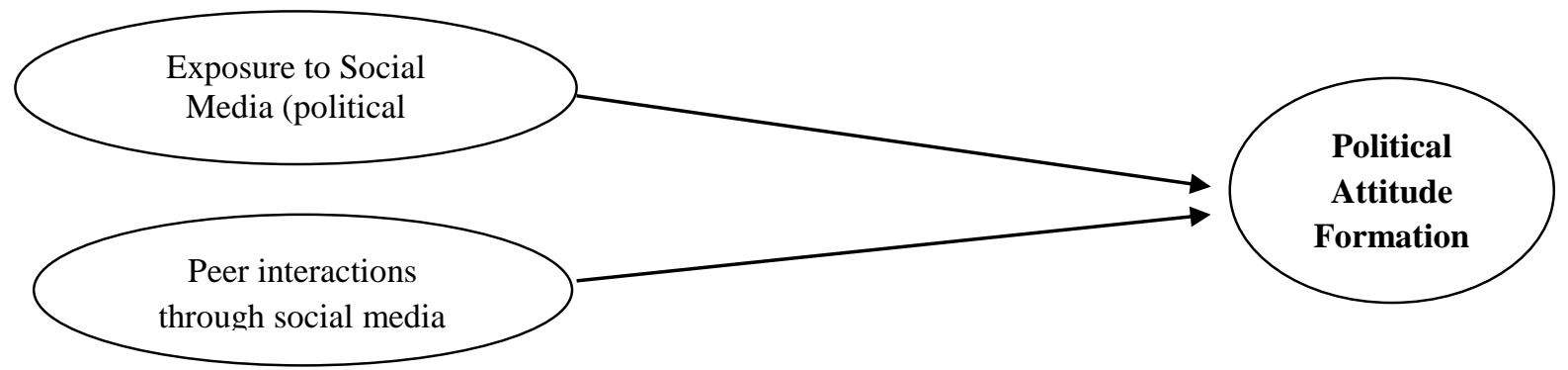

Figure 1: Research model shows political attitude formation to be dependent on exposure to social media and peer interactions through social media.

\subsection{Data Collection and Analysis}

While the Social Influence Theory was used as a theoretical lens to base the study on and achieve the research objectives, the research questions were tested on the three processes of Social Influence: Compliance, Identification and Internalization. 
An interpretivist paradigm has been adapted by the researcher and thereby the research process was undertaken following a qualitative research methodology. The case study approach investigates a contemporary phenomenon within its real-life context (Yin, 1994). Thereby, in order to understand how first time voters are influenced in their attitude formation process, how they make sense of the impact of social media marketing and online peer relationships and through these experiences, to study how the different processes of social influence affect the attitudes formed, the researcher used a case study approach to find solutions to the issue at hand, while selecting the University of Colombo as the research context. This has been justified based on the three most important factors that define an 'active social media user' - age, education and access to high speed internet. The researcher selected the individual undergraduate student, who is an active social media user and who was a first time voter in the 2010 presidential election, as the unit of analysis (Figure 2).

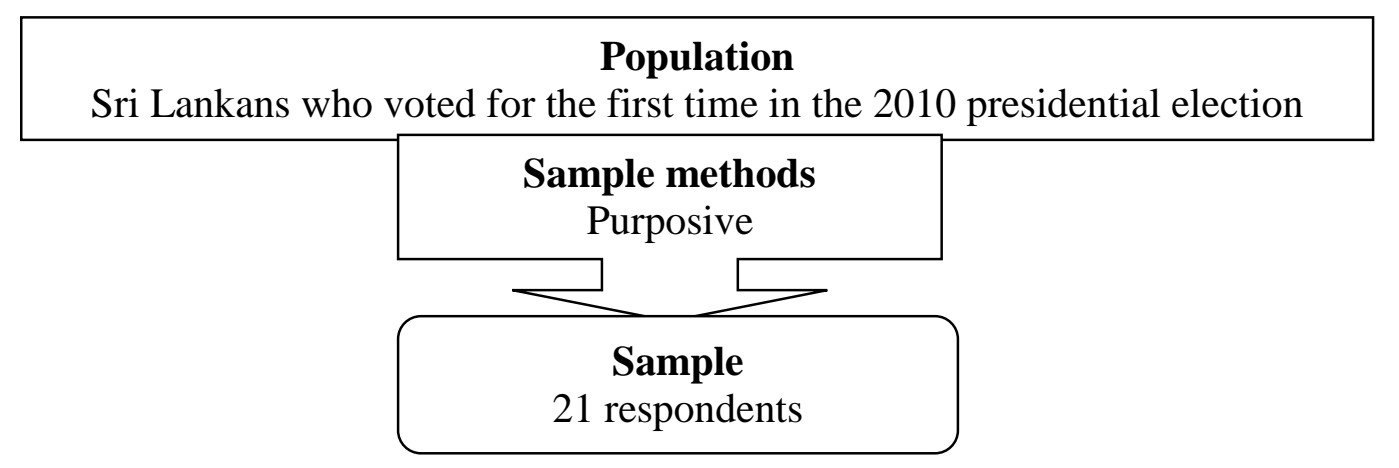

\section{Figure 2: Sampling Strategy}

Data was collected through semi structured in-depth interviews. The interviews were conducted at convenient locations selected by the respondents themselves, at pre-scheduled dates and times. They ranged in length from 40 minutes to 1.5 hours. Throughout the data collection process, field notes, write ups, contact summary sheets, and memos were drawn up to help identify and reflect on the main concepts, themes, issues and questions that emerged. 
Table 1: Sample Composition of Interviewees

\begin{tabular}{|lllll|}
\hline Faculties & \multicolumn{2}{l}{ Interviews conducted } & \multicolumn{2}{l|}{ Interviews used for study } \\
\hline & Male & Female & Male & Female \\
\hline Management & 05 & 02 & 05 & $\mathbf{0 2}$ \\
\hline Law & 02 & 06 & 02 & $\mathbf{0 5}$ \\
\hline Science & 05 & 02 & 03 & $\mathbf{0 2}$ \\
\hline Arts & 03 & 01 & 02 & - \\
\hline \hline TOTAL & $\mathbf{1 5}$ & $\mathbf{1 1}$ & $\mathbf{1 2}$ & $\mathbf{0 9}$ \\
\hline
\end{tabular}

The researcher used Thematic Analysis for analysing data and an exhaustive coding process that involved three levels of coding. This involved searching across a data set - in this case, across the number of interviews conducted - to find repeated patterns of meaning; both within and cross-case analysis was carried out to identify relevant themes. The process of coding is a part of analysis, as the data is being organized in to meaningful groups. In the current study, the researcher has followed a theoretical (deductive approach), where the data was coded for the specific research questions identified in the study (Braun \& Clarke, 2006). This approach tends to be driven by the researcher's theoretical interest in the area of study; that is, using a deductive approach helped the researcher analyze the political attitude formation of first time voters through the theoretical lens of the Social Influence theory in a detailed manner. The initial coding was done by writing notes on the interview texts and using coloured pens to indicate potential patterns, and when determining the key codes, the researcher also took in to consideration the research issue, research questions, related literature and background information on the research issue and theories selected. After repeatedly going through the interview transcriptions, write ups, field notes, and contact summary sheets, a total of 61 initial codes were identified from the 21 interviews used for analysis. These were then refined and categorized in to 17 higher order codes. This is the preliminary level of analysis which ultimately leads to the process of theme identification. Problematic issues were dealt with by reworking on the higher order codes, creating new ones and discarding irrelevant items where ultimately the researcher came up with 11 newly refined higher order codes. Refinement at level two resulted in the identification of a total of five major themes to address the research questions (Table 2).

While interviews of undergraduates were used as the predominant method of data collection the researcher also interviewed political marketers/coordinators supporting various political parties, who were directly involved in marketing activities for their respective political groups during the 2010 presidential election. Prolonged observations took place, of 
undergraduate students studying in various faculties of the university, in their informal meeting places such as, study areas, canteens, faculty benches, and class rooms. This helped the researcher to better understand the demographics of the respondents and how they affected the attitude formation process.

Table 2: Theme identification through the Coding Process

\begin{tabular}{|l|l|}
\hline Higher order codes & Themes \\
\hline Political online promotions & Compliance through Social Media \\
\hline Social rewards from peers & Compliance through Peers \\
\hline Need to identify with others & Identification with Peers \\
\cline { 1 - 1 } Need to maintain relationships & \\
\cline { 1 - 1 } Need to belong to a social group & \\
\cline { 1 - 1 } Propaganda (Image creation on social media) & \\
\cline { 1 - 1 } Clearly set goals & \\
\cline { 1 - 1 } Political knowledge & \\
\cline { 1 - 1 } Stability / trust on media & \\
\cline { 1 - 1 } Prepotency of peers to achieve goals & \\
\hline
\end{tabular}

\subsection{Ensuring Reliability and Validity}

The researcher addressed construct validity by getting respondents to respond freely to stimuli offered during interviews, and by avoiding issues that were irrelevant. The selected respondents met the criteria for 'active social media users' and the researcher was careful to find a mix of politically influenced individuals as well as influential individuals, in order to capture both sides of the story. Through multiple sources of evidence used, namely, interviews, observing (political) social media interactions, prolonged observation of the research context and interviews with political party marketers / coordinators, the researcher was able to provide multiple measures of the same phenomenon, hence address the issue of construct validity.

In adhering to chain of evidence, the reader of the study was allowed to derive evidence from initial research questions right up to the case study conclusions. This was achieved through movement from one portion to the other with clear cross-referencing to methodological procedures and to the resulting evidence (Yin, 1994). The use of verbatim interview transcripts, write ups, field notes and contact summary sheets made during the interview process allowed a clear supply of sufficient citations and cross checks of particular sources of evidence. 
External validity deals with establishing the domain to which a study's findings can be generalized; the case study approach adapted by the researcher helped achieve this by using the replication logic, helping generalize from one case (respondent) to another. A major threat to the validity of qualitative research can take place through the interpretation process, by using a framework. To minimize the errors, the researcher attempted to maintain a neutral tone and control her personal opinions when raising the interview questions. Thematic analysis being a widely accepted and used qualitative analytic method (Boyatzis, 1998), this methodologically sound process was used in analyzing the collected data.

Reliability of the study was met by taking maximum effort to document as many steps as possible of the research conducted. This was done with the help of a case study protocol. Development and refinement of the case study protocol in the research design phase was done by conducting a pilot study to test the interview questions and its structure. Peer reviews and expert reviews were also used. Reliability can also be enhanced by getting an independent assessment of transcripts, which was done using selected peers.

\subsection{Findings and Discussion}

\subsection{Political Attitude formation through social media exposure: compliance}

Political attitude formation takes place at the level of Compliance when an individual is influenced in order to get a favourable reaction from the other party. The objective might be to gain specific rewards or avoid specific punishments. In motivational theory, this expectation is defined as the need for acceptance and approval (Reiss, 2000, 2004). The Social Influence theory recognises it as a rather superficial change.

In exploring public conformity (compliance) with regard to social media exposure, the researcher identified that people accept influence (public conformance), in order to get certain rewards (promises) offered by political candidates who launch political promotions on social media. Benefits or rewards that are promised by the politician to the electorate through social media campaigns, induce people in to supporting that particular political party.

${ }^{15}$ ART 4: $x x x x x x x x x^{16}$ talked about the job field and for people to join him if they wanted an advantage ... and when they had gone to get a sponsorship in the campus, he had told them he needed a lot of support from the campus ... I guess he targets them.

\footnotetext{
${ }^{15}$ Representation of the four faculties: ART- Arts, MGT-Management, LAW-Law, SCI-Science
} 
Respondents recalled many Facebook profiles created during the presidential election of 2010, such as The Young Federation, 'Tharuna Saviya', Green Blood, Join hands for a better future, Next president of Sri Lanka, 'Thaarunyata Hetak', a citizen journalism website Groundviews, and Lanka e-news - profiles that specifically targeted the young generation, while promising them a prosperous future.

\subsection{Political Attitude formation through social media exposure: identification}

In their exposure to social media campaigns, the respondents tried to maintain their self definitions as group members on various political social media networks. The need to belong to a social media group emerged through the need to maintain their role relationships with fellow group members. Table 3 shows the higher order codes and clusters formed within 'Identification'.

Table 3: Higher Order Codes Identified from the Influence Process 'Identification'

\begin{tabular}{|l|l|l|}
\hline Higher order codes & Clusters & Theme \\
\hline Need to belong to social media & Identification with social & \multirow{2}{*}{ Identification } \\
\cline { 1 - 1 } Need to identify with others & Identification with peers & \\
\cline { 1 - 1 } Need to maintain relationships & & \\
\hline
\end{tabular}

However, the need to identify with a social media group took the lowest frequency in the data gathered and was identified only in the Faculty of Management and Finance. No other respondent in the other three faculties disclosed to having being influenced through this process.

\subsection{The role of Propaganda in the influence process of Identification}

Politicians are found to be performers, competing to be the best performer in order to win the crowd (Maarek, 1995; Newman, 1999b). Due to the modernization of politics over the years, politicians of today are eagerly engaging in various marketing tactics in order to get the political support from the electorate. Political propaganda appeared to be a popular marketing activity followed by politicians and political parties on social media networks, and this was done through various activities such as, projecting a positive image of the politician and party through symbols, pictures, and slogans, spreading misleading rumours and lies about rival politicians / parties, promoting heroic public images, and persuading people to support ideologies.

${ }^{16}$ Real politicians' identity not revealed 


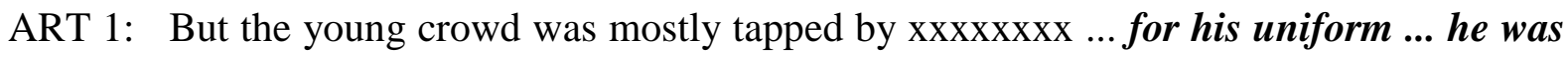
not advertised in the white outfit ... the young crowd mostly accepted him ... and his image was built as a hero.

MGT 2: A few of us got together and spread gossip about them... for instance when $\operatorname{xxx} \operatorname{xxxx}$ or $\operatorname{xxx} \operatorname{xxxxx}$ bought a small piece of land, we were supposed to exaggerate it in to saying they bought hotels, hospitals and they were the owners, to our group friends online ... now its not there ... but it was there at that time... to show that its not a lie, we chose a fact which was a small truth and attached a bigger lie to it ... the purpose

was to spread it at a national level.... we were given proof and told to spread it ... we were the 2nd link in this gossip chain ... this was mainly done through online.

\subsection{Political Attitude formation through peer interactions on social media: compliance}

It was found that during engagement of peer interactions on social media, some first time voters expected social approval from their peers. This is the social effect expected in adopting the induced behaviour. In this situation, the private beliefs of the individual may be completely different. Some of the social rewards expected by first time voters were influential friends, and job opportunities. The following depicts the power of influence senior students have over junior students, in promising them social rewards.

LAW 5: Our final year seniors will tell you if you talk to them... there were 3 or 4 ...we were taken when we were first years ... so the third years invited us to join their canvassing (online and offline) last year specially.

$L A W 3$ : When we are in the 2nd year, it is very easy to influence the first years so through that, it was easy to make them vote according to your preference and influence ... so when they come to campus its easy to change and influence them ... and they are still not very experienced in the field of politics.

When students start their first year in a faculty, they are exposed to various influences by their seniors. Apart from having direct, face-to-face interactions with peers (seniors), they are also approached by peers through social media sites such as the Facebook, asked to join social media political fan groups, discussion forums etc., and regularly get tagged on political related updates. Despite personal political views, and possibly due to lack of political 
experience and thereby, political knowledge, (as suggested by the findings), the first year students (first time voters) usually accept their seniors' requests in order to get social approval.

Out of the five attributes identified by Keller and Berry (2003), senior university students seem to take on the role of 'activists' (who are involved in political movements), 'connected' (with large social networks), and 'impact' (who are looked up to and trusted by others). That is, senior students are able to influence their junior peers due to their own involvement in political movements, their connectedness with social media networks and being looked up to and trusted by others.

Peers who are perceived to be of 'high status', that is, who are connected to influential political parties or officials, seem to be better influencers due to the simple reason that the social rewards they offer are more attractive than that of the average peer. Literature supports this view, as it is found that at the social group level, reinforcement and support provided by specific types of peers enhance influence (Prinstein \& Dodge, 2008).

\subsection{Political Attitude formation through peer interactions on social media: identification}

As per the data gathered, the two most common social influence dynamics highlighted here were the need to identify with others and the need to maintain relationships.

The 'need to identify with others' emerged as a major theme in the study, and can be explained in two forms:

1. Need of undergraduates to identify with peers who directly worked for politicians.

2. Need of junior students (mostly first years) to identify with senior peers.

The 'need to maintain relationships' arose as first year students who are new to the university, are keen to be accepted by senior students and in attempts to get in to popular social circles and thus maintain social relationships (offline and online), they are willingly induced in to forming political attitudes.

LAW 5: But I know I have managed to influence my friends! That is, I have changed my friends... I feel about 50 or 60 people changed due to my individual influence ... therefore, there must have been a lot of people who changed because of our active role in politics. 
The research findings showed that, online peer interactions were more significant than mere exposure to social media campaigns. That is, as confirmed by many respondents, peer interactions through social media initiated the exposure to social media political campaigns for first time voters. Data findings clearly show that students, who directly worked with political marketers, played a prominent role in introducing social media political campaigns to their peers.

MGT 2: Mostly it was after meeting $\operatorname{xxxxxxxx}$ aiya in my first year ... gave me a coordinator position ... told me to get together the $1^{\text {st }}$ year $s . .$. then I went to meetings ... now there's one section who says they are for Mahinda ... another group who doesn't support anyone in particular ... we are told to target them mostly ... to get them to come for meetings ... I have seen them, when talking online ... when I argue, people on both sides ... that I can influence the people who are in the middle path..

\subsection{Political Attitude Formation through the Influence process of Internalization}

The findings highlighted that the process of Internalization is integrated with an individual's intrinsic value system (independent of an external source) and directly related to his personal goals. This seemed to be manifested in the form of expectations one has for the country's future development (which can help them achieve their personal goals) and it was found that social media helps align political parties and politicians with the long term expectations of first time voters. For instance, (social media) political campaigns that give promises for a better future, and politicians who maintain regularly updated sites seem to convince people that by keeping them in power, peoples' personal goals also can be achieved. A possible reason behind the emphasis laid on pursuing personal goals with regard to the universitygoing youth, may be their pursuit of higher education and thereby higher aspirations for a better future.

Table 4: Higher Order Codes Identified from the Influence Process 'Internalization'

\begin{tabular}{|l|l|}
\hline Higher order codes & Themes \\
\hline Personal values and goals & \multirow{2}{*}{ Internalization } \\
\cline { 1 - 1 } Power of the influencing agent & \\
\cline { 1 - 1 } Stability and trust on (social) media & \\
\hline Political knowledge & \\
\hline
\end{tabular}




\subsubsection{Power of the influencing agent}

The influence process of Internalization occurs based on the agent's credibility, which is characterised by expertness and trustworthiness; an agent is perceived as credible because he is likely to know the truth and because he is likely to tell the truth (McCroskey, 1966). In the exposure to social media, and more importantly in peer interactions through social media, the agent's credibility made them an attractive source, especially when compared to controllability (through compliance) and attractiveness (through identification), thus, the influence process of internalization was most strongly identified with the power of the agent.

SCI 1: Not only regarding this, but during election times we are only talking about this, because most of my friends are sons of ministers, and both main political party friends I have ... my school mates one of my friends.. I told you...the son of the coordination secretary has become a member of the (social media) group... of that person... and after that I became a member.

\subsubsection{Stability and trust on (social) media}

Social media networks were perceived to be trustworthy and stable. While trustworthiness is also used to distinguish the credibility of information sources as explained in the previous section, stability of a media will have a strong hold on its recipients in making it an attractive tool to depend on. In general the respondents seemed to agree that social media was more attractive as a communication media, than traditional media. The data findings conclude that exposure to political campaigns on a highly reliable and trustworthy media, peer interactions that take place on such reliable media and the credibility of peers interacting on social media will lead to private acceptance of influence, which is likely to be relatively long lasting (internalization). Literature seems to support this view as it is found that online communicators tend to be more willing to disclose personal information and to be more honest and forthcoming with their viewpoints (Roed, as cited in Sun, et al., 2006). This selfdisclosure tendency might be due to the greater anonymity offered by the Internet.

SCI 3: But for the young crowd that's the best way to reach them id say ... as in for the young urban crowd. Most of our normal communication happens through FB, as in when there's a batch meeting, when there's an assessment that we don't know about, there's always an FB message. When someone has done a practical exam they say what they know online and someone else can go and read it online and help themselves. 
LAW 3: Apart from the papers I think the internet is a really good method of getting things around on ... and especially on political issues ... yeah, there is a big connection.

\subsubsection{Political knowledge}

According to the data collected, social media is seen as a rich information source in gaining political knowledge. Thus, political knowledge is acquired through two sources simultaneously - one, through the social medium itself and two, through peer interactions that take place on social media.

MGT 6: So I search the internet for the accuracy of a certain piece of news ... not only that, sometimes I listen to certain political forums and discussions.

ART 4: I mean the youth crowd by educated ...that is, they have a better knowledge than others ... the fact that they go on the internet and Facebook, means they have a relatively better knowledge... thus, from that they ... at least they get to read because of that.

In considering the role of peer interactions on social media, it was found that peer interactions worked to reduce the uncertainty faced by a first time voter. Literature finds that individuals are more likely to follow the opinion of friends, than acquaintances or unknown peers and was most easily persuaded when the correct answer was ambiguous and/or when it was clear that the peer would know their responses (Deutsch \& Gerard, 1955). Hence, this knowledge acquired especially through peer interactions, acted as a motivator to accept influence from the agent. Having access to political knowledge seemed to convince the individual of the politician's (or political party's) credibility and its congruency with the individual's personal goals. It was also highlighted in the findings that the first time voter of today lacked the much needed knowledge in politics, in order to make accurate, informed decisions in the election process. However, the more politically experienced influencers (students who directly worked for politicians) seemed to have better political knowledge than their peers.

MGT 3: We were told to ask others to join, they told me to join too... To try to inform others through media... because we are people who support the party. According to my definition, I tell another person, because I believe my ideas and beliefs are correct, $\boldsymbol{I}$ try to spread these ideas to others, because I believe the party and its policies... by doing that I have been able to influence those people. 
Influence took place through Internalization the most for respondents in the Faculty of Science, where it seemed that political attitudes were highly driven on personal goals. Personal goals such as finding a job, and getting selected for a particular academic stream (e.g. medicine) were highlighted as conditions to show support for a politician or a political party. Similarly, in the Faculty of Law it was found that political knowledge worked as a strong base for students to be influenced through Internalization and that social media was quite frequently used by them to gain access to updated (political) information. This was due to the fact that Law students follow a range of subjects which are directly related to politics (e.g. Constitutional Law).

Based on the findings, rather than the individual's concern with the social effect of behaviour (resulting in compliance), or social anchorage of behaviour (resulting in identification), it was found that individuals were more concerned with the value congruence of their behaviour , i.e., internalization, which may reflect their interest to achieve personal goals. As identified by current research, only certain political issues are of interest to the youth, and these issues are generally those affecting the individual directly (identity politics) [Pettersen, Creely, \& Pappin, 2010]. It can thus be assumed that individuals give more importance to the achievement of their personal goals, when forming political attitudes and deciding to support a political party.

\subsection{Conclusion and Implications}

Research findings indicated that while first time voters were influenced through all three processes of influence, their political attitudes were mostly formed and driven on its ability to help them achieve personal goals. That is, individuals were more concerned with the long lasting effects of value congruence (Internalization), rather than the social effect (Compliance) or social anchorage (Identification).

While major themes were identified separately for social media exposure and online peer interactions, the researcher found that peer interactions through social media was a comparatively higher source of influence (for political attitude formation). These influential peers were mostly found to be 'high status peers' with direct political connections, who acted as strong opinion leaders. Furthermore, influence mostly occurred due to the perceived credibility of peers (through Internalization), as opposed to their controlling power (Compliance) or attractiveness (Identification). This seemed to have a direct link to the need 
to achieve personal goals, by convincing the individual of a peer's ability to help them attain such goals.

In recognizing the impact of internalization on the youth voter of the country, an implication exists here for political marketers to understand what type of goals and values need to be addressed in their (social media) political campaigns. This can be effectively handled as they are already using university undergraduates as mediators to get through to the youth voting population. Indeed, the data gathered shows that influential undergraduates (who are directed by politicians) engage in social media interactions to gauge the existing political attitudes of their peers before they initiate the influence process. This first hand information can be richly resourceful to political marketers in addressing the needs and expectations of the voting population.

\section{References}

Al-Rafee, S., \& Cronan, T.P. (2006). Digital piracy: Factors that influence attitude toward behavior. Journal of Business Ethics, 63(3), 237 - 259.

Amarasinghe, A.S. (2010). Social Media Marketing. Presentation on 'Jamagra' Marketing Symposium. Retrieved $\quad$ February 14, 2010, from http://www.slideshare.net/AmSam/social-media-marketing-3286109

Bjurstrom, E. (2002). Consumer socialization: How do children become consumers?. London, UK: Advertising Education Forum. Retrieved March 12, 2010, from http://www. aeforum.org/aeforum.nsfiOn451ba8d0d2d883

$880256 \mathrm{~d} 6$ 600531043/\$FILEIEB2003.pdf

Bush, A.J., Smith, R. \& Martin, C. (1999). The influence of consumer socialization variables on attitude toward advertising: A comparison of African-Americans and Caucasians. Journal of Advertising, 28(3), 13 - 24.

Christopher, M., Payne, A., \& Ballantyne, D. (2005). A stakeholder approach to relationship marketing strategy: The development and use of the "six markets" model. European Journal of Marketing, 39(7/8), 855 - 871.

Common Wealth Report (Report of the Commonwealth expert Team): SRI LANKA PRESIDENTIAL ELECTION. Retrieved June 8, 2010, from http://www.thecommonwealth.org/files/ 
Dean, D., \& Croft (2001). Friends and Relations: Long term approaches to political campaigning. European Journal of Marketing, 35 (11/12), 1197-1216.

Deutsch, M., \& Gerard, H. B. (1955). A study of normative and informational social influences upon individual judgment. Journal of Abnormal and Social Psychology, $51,629-636$.

Henneberg, S.C.M. (2002). Understanding Political Marketing. In O'Shaughnessy, N.J. \& Henneberg, S.C.M. (Ed.), The Idea of Political Marketing. U.S.A.: Praeger Publishers.

Hess, R.D., \& Torney, J.V. (2006). The development of political attitudes in children. New Jersey, USA: Transaction Publishers.

Hovland, C. I., Janis, I. L., \& Kelley, H. H. (1953). Communications and persuasion: Psychological studies in opinion change. New Haven, CT: Yale University Press.

Johansson, E. E., Hammarström, A., Lehti, Danielsson, U., \& Bengs, C. (2009). Gaps between patients, media, and academic medicine in discourses on gender and depression: A metasynthesis. Qualitative Health Research, 19(5), 633-644.

Katz, D. (1960). The functional study of attitudes. Public Opinion Quarterly, 24, 163-204.

Keller, E., \& Berry, J. (2003). The influentials. USA: Soundview Executive Book Summaries.

Kelman, H. C. (1958). Compliance, identification, and internalization: Three processes of attitude change. Journal of Conflict Resolution, 1, 51-60.

Kelman, H. (1961). Processes of opinion change. Journal of Public Opinion, 25, 57-78.

Kelman, H. C. (1974). Attitude formation and change - Attitudes are alive and well and gainfully employed in the sphere of action. American psychologist, 310-325.

Kelman, H. C. (2002). The role of action in attitude change. In Howe, H. E., \& Page, M. M. (Ed.), Nebraska Symposium on Motivation, 1979: Attitudes, values and beliefs (pp. 117-194). Lincoln: University of Nebraska Press.

Owen, L. (1999). Effects of electronic media on democratic attitudes. Paper presented at the Globalization of Politics and the Economy International Conference. 
Maarek, P. J. (1995). Political marketing and communication. London: Libbey.

McCombs, M. E., \& Shaw, D. L. (1972). The agenda-setting function of mass media. Public Opinion Quarterly, 36, 176-187.

McCroskey, J. C. (1966). Scales for the measurement of ethos. Speech Monographs, 33, 6572.

McLean, L., \& McMillan, A. (2009). The Concise Oxford dictionary of Politics ( ${ }^{\text {rd }}$ ed.). USA: Oxford University Press Inc. New York.

Mitra, S. K., Enskat, M., \& Frey, K. (2002). Youth and the challenge of democratization: A comparative study of survey data from India and Sri Lanka. In Hettige, S. T., \& Mayer, M. (Ed.), Youth and Youth Research in Sri Lanka. Sri Lankan Youth: Challenges and Responses. (pp. 142-176). Sri Lanka: Friedrich Ebert Stiftung.

Moschis, G.P., \& Churchill, G.A. (1978). Consumer socialization: A theoretical and empirical analysis. Journal of Marketing Research, XV, $599-609$.

Moschis, G.P., \& Moore, R.L. (1979). Decision making among the young: A socialization perspective. The Journal of Consumer Research, 6(2), $101-112$.

Newman, B. (1999a). Handbook of political marketing. Thousand Oaks, CA: Sage Publications.

Newman, B. (1999b). The mass marketing of politics. Thousand Oaks, CA: Sage Publications.

Pettersen, J., Creely, M., \& Pappin, A. (2010). Youth media for Europe: Perspectives on youth, media and politics. Dublin: Centre for Social \& Educational Research Dublin Institute of Technology.

Prinstein, M. J., \& Dodge, K. A. (2008). Understanding peer influence in children and adolescents. New York: The Guilford Press.

Rao, Akshay R., Childers, T.L., \& Dutta, S. (1991). Theoretical perspectives on intergenerational influences in consumer behavior. Working paper, Department of Marketing, Univesrity of Minnesota, U.S.A.

Reiss, S. (2000). Who am I: The 16 basic desires that motivate our actions and define our personalities. New York: Tarcher/Putnam. 
Reiss, S. (2004). Multifaceted nature of intrinsic motivation: The theory of 16 basic desires. Review of General Psychology, 8 (3), 179-193.

Schwartzenberg, R. (1977). Politieke superstars: Vedettencultus in de politiek. Antwerpen: Standaard Uitgeverij.

Shim, S., \& Koh, A. (1997). Profiling Adolescent Consumer Decision-Making Styles: Effects of Socialization Agents and Social-Structural Variables. Clothing and Textiles Research Journal, 15, 50-59.

Sun, T., Youn, S., Wu, G., \& Kuntaraporn, M. (2006). Online word-of-mouth (or mouse): An exploration of its antecedents and consequences. Journal of Computer-Mediated Communication, 11(4), article 11. Retrieved August 5, 2010, from http://jcmc.indiana.edu/vol11/issue4/sun.html

Thangarajah, C. Y. (2002). Youth, conflict and social transformation in Sri Lanka. In Hettige, S. T., \& Mayer, M. (Ed.), Youth and Youth Research in Sri Lanka. Sri Lankan Youth: Challenges and Responses. (pp. 177-215). Sri Lanka: Friedrich Ebert Stiftung.

The World Factbook (CIA): Central Intelligence Agency. Retrieved March 6, 2010, from https://www.cia.gov/library/publications/the-world-factbook/

Vergeer, M., Hermans, L., \& Sam, S. (2013). Online social networks and micro-blogging in political campaigning: The exploration of a new campaign tool and a new campaign style. Party Politics, 19 (3), 477-501.

Ward, S. (1974). Consumer socialization. Journal of Consumer Research, 1, 1-14.

Weber, L., \& Bergman, J. (2001). Who participates and how? A comparison of citizens 'online' and the mass public. Paper presented at the Annual Meeting of the Western Political Science Association, March. 